\title{
Significance of ABCA1 in human carotid atherosclerotic plaques
}

\author{
HEANG-FANG LIU ${ }^{1 *}$, KE-FEI CUI ${ }^{2 *}$, JIAN-PING WANG ${ }^{1}$, MIN ZHANG ${ }^{1}$, \\ YA-PEI GUO ${ }^{1}$, XUE-YUAN LI $^{3}$ and CHAO JIANG ${ }^{1}$ \\ Departments of ${ }^{1}$ Neurology, ${ }^{2}$ Ultrasound, and ${ }^{3}$ Neurosurgery, Fifth Affiliated Hospital, \\ Zhengzhou University, Zhengzhou, Henan 450052, P.R. China \\ Received January 28, 2012; Accepted March 20, 2012
}

DOI: $10.3892 / \mathrm{etm} .2012 .576$

\begin{abstract}
The ATP-binding cassette transporter A1 (ABCA1) is an important effector in the regulation of cholesterol efflux from cells. In this study, we assessed the role of ABCA1 in human carotid atherosclerotic plaques (CAPs). We found that $\mathrm{ABCA} 1$ and retinoid $\mathrm{X}$ receptor $\alpha(\mathrm{RXR} \alpha)$ mRNAs were significantly increased in the atherosclerotic plaques compared to control arteries. The increased ABCA1 mRNA correlated with that of $\mathrm{RXR} \alpha$ in plaques. According to the modified American Heart Association plaque classification, atherosclerotic specimens were assigned to three grades, and ABCA1 and RXR $\alpha$ mRNA levels were compared across plaques of different grades. Resultantly, plaques of grade II and III exhibited higher mRNA levels than grade I, but there was no difference in mRNA levels between plaques of grade II and III. By contrast, ABCA1 and RXR $\alpha$ protein levels were notably reduced in plaques relative to control tissues. Similarly, plaques of grade II and III exhibited lower ABCA1 and $\mathrm{RXR} \alpha$ protein levels than grade I, and there was no difference in protein levels between plaques of grade II and III. Our findings suggest that decreased ABCA1 protein plays a key role in the pathogenesis of CAP; the regulation of ABCA1 may be mediated by RXR $\alpha$ and ABCA1 mRNA levels may serve as an indicator for plaque stability.
\end{abstract}

\section{Introduction}

Carotid atherosclerotic plaque (CAP) is a predominant established risk factor for stroke, which is associated with high morbidity and mortality (1). Although the development of carotid plaques is influenced by environmental factors, such as elevated blood pressure and serum lipoprotein abnormalities (2),

Correspondence to: Dr Jian-Ping Wang, Department of Neurology, Fifth Affiliated Hospital, Zhengzhou University, No. 3 Kang-fu Street, Er-qi, Zhengzhou, Henan 450052, P.R. China

E-mail: jianpingwang1208@126.com

\section{*Contributed equally}

Key words: atherosclerosis, ATP-binding cassette transporter A1, carotid atherosclerotic plaques, retinoid $\mathrm{X}$ receptor $\alpha$ studies have been increasingly focusing on the genetic causes associated with the formation of atherosclerosis. ATP-binding cassette transporter 1 (ABCA1) has been recognized as a major mediator in the initial step of the reverse cholesterol transport, and was shown to facilitate the efflux of cholesterol and phospholipids to lipid-poor apolipoproteins (apo)A-I and apoE from peripheral cells, resulting in the formation of nascent or pre-high-density lipoprotein (HDL) $(3,4)$. Such a cholesterol efflux process prevents the accumulation of cholesterol or oxidative low-density lipoprotein (LDL) in peripheral cells, including macrophages within the arterial wall and, therefore, reduces the accumulation of atherosclerotic plaque.

ABCA1 deficiency was indentified to be responsible for Tangier disease and familial HDL deficiency. These conditions are characterized by low levels of HDL, excessive deposition of cholesteryl esters in tissue macrophages and an increased risk for atherosclerotic disease (5). The underlying mechanism is thought to result from the failure of ABCA1 to transport cholesterol and phospholipids out of cells to form complexes with apolipoproteins to generate HDL (6). The intracellular sterol accumulation and subsequent development of foam cells may, as a result, lead to the atheromatous plaque. Due to its important role in atherosclerosis, increasing attention has been focused on ABCA1, so that therapeutic interventions are introduced to regulate its expression and therefore reduce the development of atherosclerosis.

The expression and significance of ABCA1 have been well reported in animals with ABCA1 overexpression or inactivation (7), as well as in individuals with ABCA1 gene deficiency due to gene mutations (8). Although the systemic effects of loss of function have been well investigated in patients with ABCA1 deficiency, few studies have addressed in detail the possible effect of the transporter on plaque complication in localized atherosclerosis in the absence of familial gene mutations. Identification of the ABCA1 expression in localized lesions may provide new insights into local genetic determinants of atheromatous disease without mutations in the gene and therefore the development of new therapeutic strategies.

In this study, we assessed the expression of the ABCA1 gene and protein in human CAPs and compared it to human arteries obtained from normal controls. Also, we classified the plaques into three grades according to the American Heart Association (AHA) and characterized the ABCA1 expression in the CAPs of different grades. Furthermore, to gain further 
insight into the regulatory mechanism underlying ABCA1 expression, we determined the expression of one of its key regulators, retinoid $\mathrm{X}$ receptor $\alpha(\mathrm{RXR} \alpha)$.

\section{Materials and methods}

Patients and specimens. We collected CAPs from 48 patients undergoing carotid endarterectomy for symptomatic (transient ischemic attacks, minor strokes) or asymptomatic stenosis $>70 \%$ confirmed by MR angiography or conventional arteriography. All patients underwent detailed history assessment and a physical examination at baseline that included routine blood biochemistry tests, electrocardiography, chest radiography, ultrasound cardiography, transcranial Doppler sonography, carotid CEMRI, computed tomography, MRI and magnetic resonance angiography of the brain. In addition, the presence of vascular risk factors as well as previous antihypertensive, statin and antiplatelet treatments were recorded (Table I). We also collected 10 inferior mesenteric arteries dissected from colectomy specimens of subjects having elective operation as normal controls. The control patients were assessed for the absence of symptomatic atherosclerotic disease by history and examination.

The endarterectomy specimens included the atheromatous plaque, the adjacent intima and the medial layers. The collected 48 specimens were assigned to three grades according to the modified AHA classification (9): 14 cases of grade I (type I and II), which was defined as a diffuse intimal thickening or small eccentric plaque without calcification; 22 cases of grade II (type III and IV), which was described as plaque with a lipid or necrotic core surrounded by fibrous tissue with possible calcification; 12 cases of grade III (type V and VI), presenting complex plaques with a possible surface defect, hemorrhage or thrombus. The control arteries were of full-thickness and consisted of the adventitial layer. Plaques and control arteries were frozen immediately in liquid nitrogen and stored at $-80^{\circ} \mathrm{C}$ until further processing. Sections from control arteries were stained with $\mathrm{H} \& \mathrm{E}$ and assessed by a histopathologist for evidence of age-related atheromatous change.

The study was approved by the Medical Ethics Committee of the Fifth Affiliated Hospital of Zhengzhou University, and informed consent was obtained from each patient.

Reverse transcriptase-polymerase chain reaction (RT-PCR). The ABCA1 and RXR $\alpha$ mRNA expression levels were determined using semi-quantitative RT-PCR. Total RNA was isolated from freshly isolated pulverized frozen tissue $(\sim 25 \mathrm{mg})$ with TRIzol reagent (Invitrogen) and solubilized in RNAasefree water. The first-strand cDNA was synthesized from $2 \mu \mathrm{g}$ of total RNA with PrimeScript Reverse Transcriptase (Takara Bio). The sequences of the specific primers used are shown in Table II. Specific primers for glyceraldehyde3-phosphate dehydrogenase (GAPDH; Clontech) were added as a control. PCR was carried out by incubating each cDNA sample with primers $(0.5 \mu \mathrm{M}$ each), Blend $T a q$ polymerase (1.25 units; Takara Bio) and a deoxynucleotide. For ABCA1, PCR was run for 35 cycles with $30 \mathrm{sec} / 94^{\circ} \mathrm{C}$ denaturation, $40 \mathrm{sec} / 52^{\circ} \mathrm{C}$ annealing and $45 \mathrm{sec} / 72^{\circ} \mathrm{C}$ elongation. For RXR $\alpha$, PCR was run for 38 cycles with $30 \mathrm{sec} / 94^{\circ} \mathrm{C}$ denaturation, $45 \mathrm{sec} / 58^{\circ} \mathrm{C}$ annealing and $40 \mathrm{sec} / 72^{\circ} \mathrm{C}$ elongation. Reactions
Table I. Clinical characteristics of the patients and controls.

\begin{tabular}{lcc}
\hline & Patients & Controls \\
\hline No. & 48 & 10 \\
Age (years) & $56.2 \pm 7.3$ & $55.9 \pm 10.1$ \\
Gender (male/female) & $34 / 14$ & $7 / 3$ \\
Smokers & 26 & 4 \\
Diabetes & 12 & 0 \\
Hypertension & 30 & 3 \\
Coronary artery disease & 14 & 0 \\
Family history of IHD & 22 & 2 \\
Treatment & & \\
Aspirin & 20 & 1 \\
Clopidogrel & 2 & 0 \\
Warfarin & 4 & 0 \\
Statins & 14 & \\
\hline
\end{tabular}

IHD, ischemic heart disease.

were performed in triplicate and in a total volume of $25 \mu 1$. PCR products were electrophoresed on $1 \%$ agarose gels. Bands were stained with ethidium bromide (Sigma) and detected with a LAS-3000 mini CCD camera (Fuji Film). The Eagle Eye II analyzer (USA) was used to determine the optical density (OD) of target and reference mRNA. The mRNA levels were recorded as the relative value of the OD of the target gene to that of GAPDH.

Western blotting. The content of ABCA1 and RAR $\alpha$ protein was detected by western blot analysis. The frozen tissues were pulverized and sonicated in RIPA lysis buffer (Santa Cruz). After centrifugation at $14,000 \mathrm{x}$ g for $30 \mathrm{~min}$ at $4^{\circ} \mathrm{C}, 30 \mu \mathrm{g}$ of the supernatants was separated on $10 \%$ SDS-polyacrylamide gel and transferred onto Immobilon-P transfer membrane (Millipore). After being blocked with 5\% skim milk, the membrane was incubated with the primary ABCA1 antibody (dilution at 1:1,000; Abcam) or the primary RAR $\alpha$ antibody (dilution at 1:1,000; Millipore) at $4^{\circ} \mathrm{C}$ overnight. Membranes were then treated with anti-rabbit secondary antibody conjugated with horseradish peroxidase (dilution at 1:1,000; Santa Cruz). Complexes on the membranes were then visualized using the Super Signal West Dura Extended Duration Substrate (Pierce Biotechnology Inc.), photographed and analyzed with the Eagle Eye II analyzer. The relative value of the absorbance value of the target protein to the reference protein was recorded.

Statistical analysis. Results are presented as the means \pm SEM. Statistical analysis was performed with SAS 9.0. Gender differences between patient and control groups were assessed using the $\chi^{2}$ test. Comparisons in the ABCA1 and RXR $\alpha$ expression between patients and controls were performed using the Student's t-test or ANOVA. Relations between the ABCA1 and RXR $\alpha$ mRNA were evaluated using Pearson correlations. Differences were considered to denote statistical significance at $\mathrm{P}<0.05$. 
Table II. Sequences of the primers for PCR.

\begin{tabular}{llll}
\hline & \multicolumn{1}{c}{$\begin{array}{c}\text { Forward primer } \\
\text { sequence }\end{array}$} & $\begin{array}{c}\text { Reverse primer } \\
\text { sequence }\end{array}$ & $\begin{array}{c}\text { Product fragment } \\
(\mathrm{bp})\end{array}$ \\
\hline ABCA1 & 5'-GGGAGGCTCCCGGAGTT-3' & 5'-GTATAAAAGAAGCCTCCGAGCATC-3' & 302 \\
RXR $\alpha$ & 5'-GTATAAAAGAAGCCTCCGAGCATC-3' & 5'-GCGGCGCCTCCAGCATCTCCATA-3' & 800 \\
GAPDH & 5'-TGATGACATCAAGAAGGTGGTGAA-3' & 5'-TCCTTGGAGGCCATGTAGGCCAT-3' & 238 \\
\hline
\end{tabular}

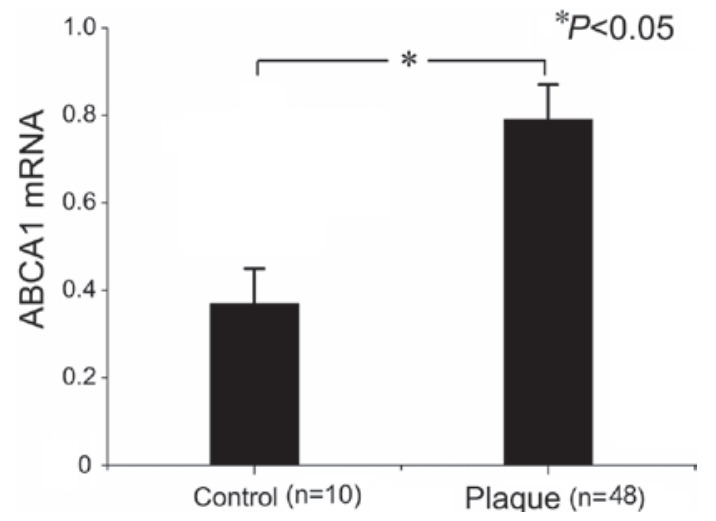

Figure 1. Expression of ABCA1 mRNA in control arteries and plaques.

\section{Results}

Patient demographics. The demographic characteristics of the patients and controls are presented in Table I. There was no significant difference between patients and controls in terms of gender, symptomatic carotid disease, individual or combined risk factors, treatment or coexistence of other vascular disease (Table I).

Expression of ABCA1 mRNA in carotid plaques. Table III summarizes the results for ABCA1 and RXR $\alpha$ mRNA levels in CAPs and control arteries. As expected, ABCA1 mRNA was significantly increased in the plaques compared to controls (Fig. 1). When we compared ABCA1 mRNA expression across plaques of different grades, we found higher ABCA1 mRNA levels in plaques of grade II and III compared to those of grade I (Table III, Figs. 2 and 3). However, ABCA1 mRNA in plaques of grade III was not significantly higher than that of grade II (Table III). To explore the potential underlying mechanism, the RXR $\alpha$ mRNA levels were also determined and correlated to the ABCA1 mRNA expression. As a result, we found a parallel evolving pattern between RXR $\alpha$ and ABCA1 mRNA expression. Furthermore, a significant association between ABCA1 and $\mathrm{RXR} \alpha \mathrm{mRNA}$ expression levels was observed in the plaques (Fig. 4A), but no correlation was found in the control arteries (Fig. 4B), suggesting the coordinative actions between ABCA1 and RXR $\alpha$ mRNA in the plaques.

Expression of ABCA1 protein in carotid plaques. Table IV summarizes the results for ABCA1 and RXR $\alpha$ protein levels in CAPs and control arteries. In contrast to mRNA levels, ABCA1 protein was significantly reduced in the plaques as compared to control arteries (Figs. 5 and 6, Table IV). The
Table III. Expression of ABCA1 and RXR $\alpha$ mRNA in plaques and control arteries.

\begin{tabular}{lll}
\hline & ABCA1 mRNA & RXR $\alpha$ mRNA \\
\hline Plaques & & \\
Grade I $(\mathrm{n}=14)$ & $0.67 \pm 0.05^{\mathrm{a}}$ & $0.67 \pm 0.03^{\mathrm{a}}$ \\
Grade II $(\mathrm{n}=22)$ & $0.97 \pm 0.05^{\mathrm{a}, \mathrm{b}}$ & $0.95 \pm 0.05^{\mathrm{a}, \mathrm{b}}$ \\
Grade III $(\mathrm{n}=12)$ & $0.77 \pm 0.04^{\mathrm{a}}$ & $0.74 \pm 0.04^{\mathrm{a}}$ \\
Control arteries $(\mathrm{n}=10)$ & $0.37 \pm 0.04$ & $0.39 \pm 0.04$ \\
\hline
\end{tabular}

${ }^{\mathrm{a}} \mathrm{p}<0.05$ vs. control arteries; ${ }^{\mathrm{b}} \mathrm{p}<0.05$ vs. control arteries.

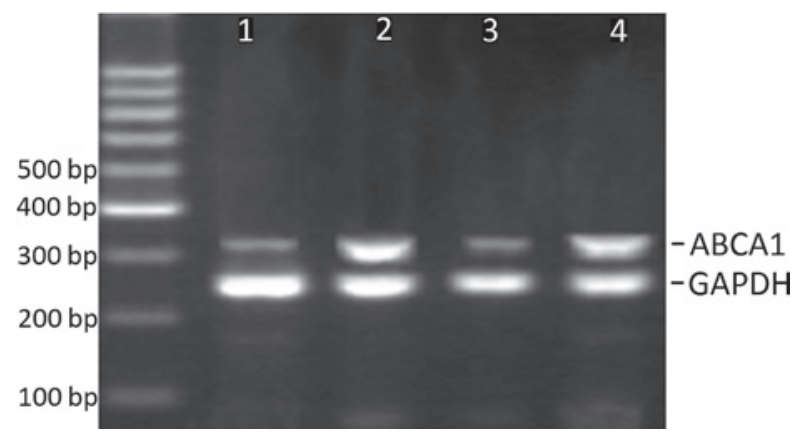

Figure 2. PCR for ABCA1 mRNA in control arteries and plaques. Lanes 1 and 3 are samples from control arteries. Lane 2 is a sample from plaques of grade I. Lane 4 is a sample from plaques of grade II.

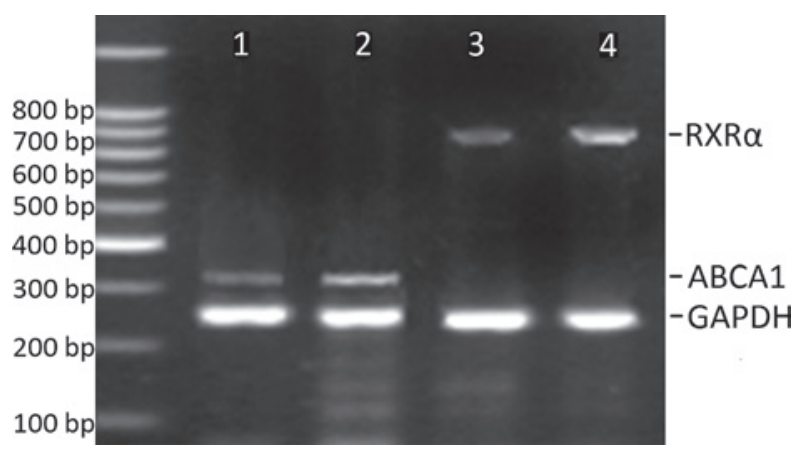

Figure 3. PCR for ABCA1 and RXR $\alpha$ mRNA in control arteries and plaques. Lanes 1 and 3 are samples from control arteries. Lanes 2 and 4 are samples from plaques of grade III.

plaques of grade II and III exhibited lower ABCA1 protein levels than those of grade I. However, no difference was found in ABCA1 protein levels in plaques of grade II and III 

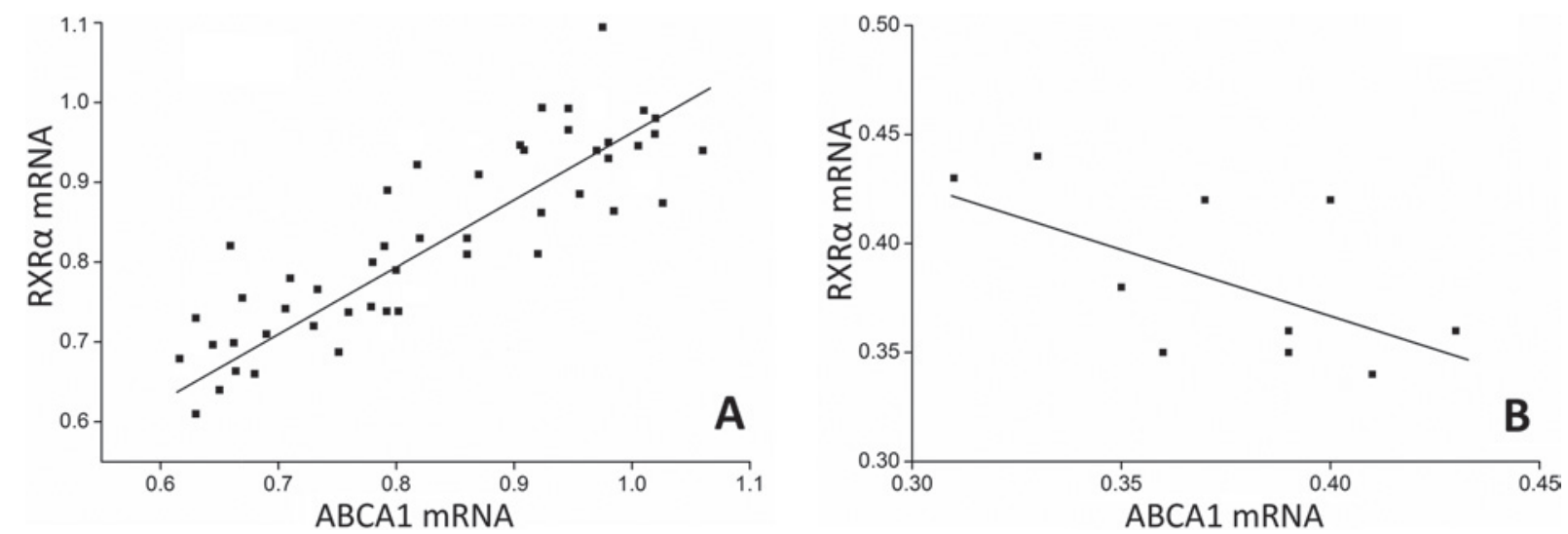

Figure 4. Correlation between ABCA1 and RXR $\alpha$ mRNA levels in (A) plaques and in (B) control tissues. ABCA1 and RAR $\alpha$ mRA levels in (A) plaques and (B) control arteries were determined with RT-PCR and normalized to GAPDH.

Table IV. Expression of ABCA1 and RXR $\alpha$ protein in plaques and control arteries.

\begin{tabular}{lcc}
\hline & ABCA1 protein & RXR $\alpha$ protein \\
\hline Plaques & & \\
Grade I $(\mathrm{n}=14)$ & $0.26 \pm 0.04^{\mathrm{a}}$ & $0.31 \pm 0.05^{\mathrm{a}}$ \\
Grade II $(\mathrm{n}=22)$ & $0.16 \pm 0.05^{\mathrm{a}, \mathrm{b}}$ & $0.18 \pm 0.03^{\mathrm{a}, \mathrm{b}}$ \\
Grade III $(\mathrm{n}=12)$ & $0.20 \pm 0.04^{\mathrm{a}}$ & $0.27 \pm 0.04^{\mathrm{a}}$ \\
Control arteries $(\mathrm{n}=10)$ & $0.53 \pm 0.03$ & $0.57 \pm 0.04$ \\
\hline
\end{tabular}

${ }^{\mathrm{a}} \mathrm{p}<0.05$. vs. group $\mathrm{B} ;{ }^{\mathrm{b}} \mathrm{p}<0.05$. vs. control arteries.

(Table IV). A similar evolving pattern was observed in the $\mathrm{RXR} \alpha$ protein expression. In the plaques, the $\mathrm{RXR} \alpha$ protein levels were significantly reduced as compared to control arteries. Although the RXR $\alpha$ protein levels were significantly lower in plaques of grade II and III compared to grade I, there was no difference between plaques of grade II and III (Table IV).

\section{Discussion}

In this study, we showed that in CAPs, both ABCA1 and RXR $\alpha$ mRNA levels were significantly increased compared to control arteries, and a parallel correlation between the mRNA levels of both genes was found. In these atherosclerotic tissues, ABCA1 and RXR $\alpha$ mRNA levels in both grade II and III were notably higher than those in grade I, but no significant difference was found in mRNA levels between grade II and III. Despite the up-regulation of mRNA expression, ABCA1 and RXR $\alpha$ protein levels were notably decreased in atherosclerotic plaques. Furthermore, although the plaques of grade I exhibited lower ABCA1 and RXR $\alpha$ protein levels, there was no difference in the levels of both proteins between plaques of grade II and III. These findings seem to be important for improving our understanding of the physiological roles of ABCA1 in localized atherosclerosis without gene mutations, and thus raise the possibility of further new therapeutic interventions targeted at $\mathrm{ABC}$ transporters in atherosclerosis.

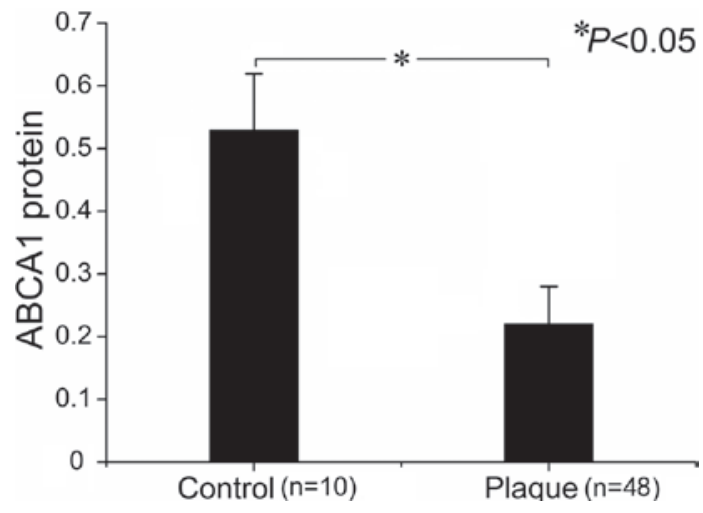

Figure 5. Expression of ABCA1 protein in control arteries and plaques.

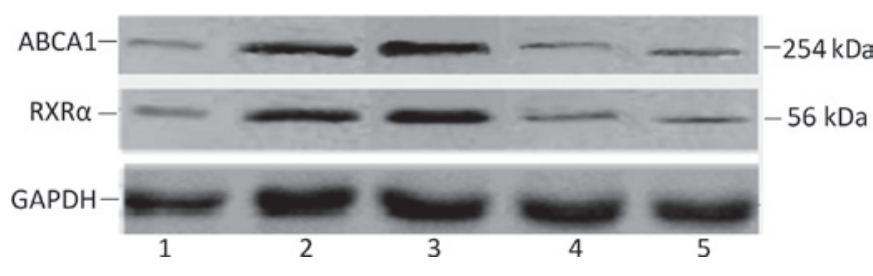

Figure 6. Western blotting for ABCA1, RXR $\alpha$ and GADPH protein in plaques and control arteries. Lane 1 is a sample from plaques of grade I. Lanes 2 is a sample from plaques of grade II. Lanes 3 and 4 are samples from control arteries. Lane 5 is a sample from plaques of grade III.

ABCA1 is a membrane transporter abundant in macrophages that utilize ATP as a source of energy to transport various molecules across membranes; its origin and pathological significance in atherosclerotic tissues was identified in animal studies of ABCA1 inactivation and human gene ABCA1 mutations (10). In these studies, loss of ABCA1 gene function was shown to play a key role in lipid deposition and its sequelae $(7,8)$. In the present study, however, we found a significant increase in ABCA1 gene expression in atherosclerotic tissues. In fact, mRNA levels did not precisely reflect protein expression and, particularly for $\mathrm{ABCA} 1$, there was a significant discordance between ABCA1 mRNA and protein levels, implying that post-transcriptional regulation plays a major role in ABCA1 protein expression (11). Since we determined the mRNA and protein levels by analyzing the 
same specimen, we speculated that, in the control arteries, the presence of ABCA1 protein reflected the expression of the gene. In the CAP specimens, however, markedly lower levels of ABCA1 protein were found compared to control tissues. These findings suggested that, although the ABCA1 transcription was significantly increased in atherosclerotic tissues, its protein expression was not increased, but reduced, in agreement with results published by Albrecht et al (12).

We showed that the plaques of grade II and III exhibited higher ABCA1 mRNA and lower protein levels than those of grade I. In terms of plaque composition, plaques of grade II and III consist of a lipid or necrotic core, which makes them unstable (13). Thus, ABCA1 may serve as an important marker for plaque instability. However, we found no significant difference in both mRNA and protein levels between plaques of grade II and III, suggesting that the unstable plaques may share a similar pattern in ABCA1 distribution. Taking into account that ABCA1 is mainly located in macrophages within the atheromatous lesion (14), the different ABCA1 expression patterns in plaques of different grades may be associated with the composition and microenvironment of the atherosclerotic lesions.

Atherosclerotic plaque is a dynamic structure composed of lipids, cells and extracellular matrix (15). In unstable atherosclerotic lesions (grade II and III), macrophages tend to accumulate large amounts of sterols (16). Increased intracellular sterol concentration in macrophages promotes ABCA1 mRNA expression not only in a time- and dose-dependent fashion $(17,18)$, but also by activating nuclear receptors, such as LXR and RXR $\alpha$ (19-21), which may explain the lower mRNA levels in plaques of grade I. Although the accumulated sterol has also been shown to up-regulate ABCA1 protein expression in a dose-dependent fashion (17), it accelerates the ABCA1 degradation in macrophages in a direct and indirect way to a greater extent (22). The sterol-rich environment inside the plaque is amplified by the low ABCA1 levels (23), which in return degrade the ABCA1 protein. Furthermore, ABCA1 has been shown to contain a PEST sequence that enhances protein degradation (24). The similar ABCA1 distribution pattern in plaques of grade II and III may be attributed to the similar composition of the three constituents (15).

The retinoid $\mathrm{X}$ receptor $(\mathrm{RXR})$ is a pleiotropic nuclear receptor transcription factor that regulates the expression of its target genes. RXR expressed in macrophages plays an important role in plaque physiology, as it activates and suppresses the ABCA1 gene expression in a RXR-responsive elementdependent manner (25). Previous studies have shown that ABCA1 transcription is stimulated by retinoid X and the LXR receptor (25), and that the induction of ABCA1 expression reflected that of $\operatorname{LXR} \alpha(12,26)$. In this study, we found that in atherosclerotic plaques, the ABCA1 and RXR $\alpha$ mRNA levels were significantly elevated, and a parallel increase in mRNA levels of both genes was observed. The observed up-regulation of ABCA1 and RXR $\alpha$ mRNA may be associated with the increased oxysterol concentration in the plaque. The ABCA1 protein may be the key factor that modulates the cholesterol homeostasis in macrophages. The increased degradation of ABCA1 protein in the plaques could result in decreased lipid efflux, accumulation of oxysterol and the stimulation of regulatory pathways through $\mathrm{RXR} \alpha$.
In summary, our findings demonstrate that the ABCA1 protein was notably reduced in atherosclerotic plaques, whereas the ABCA1 and RXR $\alpha$ mRNA levels were significantly increased. The failure of ABCA1 mRNA to translate into ABCA1 protein suggests that new interventions should be targeted at the transcriptional up-regulation of ABCA1 and its protein stabilization. Our results also show that the unstable atherosclerotic plaques exhibited higher ABCA1 mRNA levels, proposing the ABCA1 mRNA as a potential biomarker of a particular subgroup of unstable carotid plaques.

\section{Acknowledgements}

This study was supported by grants from the Zhengzhou Committee of Science and Technology (No. 083SGY2612-9).

\section{References}

1. Thorvaldsen P, Kuulasmaa K, Rajakangas AM, et al: Stroke trends in the WHO MONICA project. Stroke 28: 500-506, 1997.

2. Delcker A, Diener HC and Wilhelm H: Influence of vascular risk factors for atherosclerotic carotid artery plaque progression. Stroke 26: 2016-2022, 1995.

3. Remaley AT, Stonik JA, Demosky SJ, et al: Apolipoprotein specificity for lipid efflux by the human ABCAI transporter. Biochem Biophys Res Commun 280: 818-823, 2001.

4. Wang N, Silver DL, Thiele C, et al: ATP-binding cassette transporter A1 (ABCA1) functions as a cholesterol efflux regulatory protein. J Biol Chem 276: 23742-23747, 2001.

5. Burris TP, Eacho PI and Cao G: Genetic disorders associated with ATP binding cassette cholesterol transporters. Mol Genet Metab 77: 13-20, 2002.

6. Oram JF, Lawn RM, Garvin MR, et al: ABCA1 is the cAMPinducible apolipoprotein receptor that mediates cholesterol secretion from macrophages. J Biol Chem 275: 34508-34511, 2000.

7. Aiello RJ, Brees D, Bourassa PA, et al: Increased atherosclerosis in hyperlipidemic mice with inactivation of ABCA1 in macrophages. Arterioscler Thromb Vasc Biol 22: 630-637, 2002.

8. van Dam MJ, de Groot E, Clee SM, et al: Association between increased arterial-wall thickness and impairment in ABCA1driven cholesterol efflux: an observational study. Lancet 359: 37-42, 2002.

9. Stary HC, Chandler AB, Dinsmore RE, et al: A definition of advanced types of atherosclerotic lesions and a histological classification of atherosclerosis. A report from the Committee on Vascular Lesions of the Council on Arteriosclerosis, American Heart Association. Arterioscler Thromb Vasc Biol 15: 1512-1531, 1995.

10. Bodzioch M, Orso E, Klucken J, et al: The gene encoding ATP-binding cassette transporter 1 is mutated in Tangier disease. Nat Genet 22: 347-351, 1999.

11. Wellington CL, Walker EK, Suarez A, et al: ABCA1 mRNA and protein distribution patterns predict multiple different roles and levels of regulation. Lab Invest 82: 273-283, 2002.

12. Albrecht C, Soumian S, Amey JS, et al: ABCA1 expression in carotid atherosclerotic plaques. Stroke 35: 2801-2806, 2004.

13. Virmani R, Kolodgie FD, Burke AP, et al: Lessons from sudden coronary death: a comprehensive morphological classification scheme for atherosclerotic lesions. Arterioscler Thromb Vasc Biol 20: 1262-1275, 2000.

14. Lawn RM, Wade DP, Couse TL, et al: Localization of human ATP-binding cassette transporter 1 (ABC1) in normal and atherosclerotic tissues. Arterioscler Thromb Vasc Biol 21: 378-385, 2001.

15. Soumian S, Albrecht C, Davies AH, et al: ABCA1 and atherosclerosis. Vasc Med 10: 109-119, 2005.

16. Tabas I: Free cholesterol-induced cytotoxicity a possible contributing factor to macrophage foam cell necrosis in advanced atherosclerotic lesions. Trends Cardiovasc Med 7: 256-263, 1997.

17. Langmann T, Klucken J, Reil M, et al: Molecular cloning of the human ATP-binding cassette transporter 1 (hABC1): evidence for sterol-dependent regulation in macrophages. Biochem Biophys Res Commun 257: 29-33, 1999. 
18. Liao H, Langmann T, Schmitz G, et al: Native LDL upregulation of ATP-binding cassette transporter-1 in human vascular endothelial cells. Arterioscler Thromb Vasc Biol 22: 127-132, 2002

19. Costet $\mathrm{P}$, Luo Y, Wang N, et al: Sterol-dependent transactivation of the $\mathrm{ABC} 1$ promoter by the liver $\mathrm{X}$ receptor/retinoid $\mathrm{X}$ receptor. J Biol Chem 275: 28240-28245, 2000.

20. Fu X, Menke JG, Chen Y, et al: $27-H y d r o x y c h o l e s t e r o l$ is an endogenous ligand for liver $\mathrm{X}$ receptor in cholesterol-loaded cells. J Biol Chem 276: 38378-38387, 2001.

21. Wagner BL, Valledor AF, Shao G, et al: Promoter-specific roles for liver $\mathrm{X}$ receptor/corepressor complexes in the regulation of ABCA1 and SREBP1 gene expression. Mol Cell Biol 23: 5780-5789, 2003.

22. Uehara Y, Engel T, Li Z, et al: Polyunsaturated fatty acids and acetoacetate downregulate the expression of the ATP-binding cassette transporter A1. Diabetes 51: 2922-2928, 2002.
23. Schwartz K, Lawn RM and Wade DP: ABC1 gene expression and ApoA-I-mediated cholesterol efflux are regulated by LXR. Biochem Biophys Res Commun 274: 794-802, 2000.

24. Wang N, Chen W, Linsel-Nitschke P, et al: A PEST sequence in ABCA1 regulates degradation by calpain protease and stabilization of ABCA1 by apoA-I. J Clin Invest 111: 99-107, 2003.

25. Cui H, Okuhira K, Ohoka N, et al: Tributyltin chloride induces ABCA1 expression and apolipoprotein A-I-mediated cellular cholesterol efflux by activating LXRalpha/RXR. Biochem Pharmacol 81: 819-824, 2011.

26. Laffitte BA, Joseph SB, Walczak R, et al: Autoregulation of the human liver X receptor alpha promoter. Mol Cell Biol 21: 7558-7568, 2001 